\title{
POSSIBILITY OF TRANSMITTING ALARM MESSAGES OVER THE RADIO NETWORK TO THE MONITORING AND ALARM RECEIVING CENTRE

\author{
Martin Boroš ${ }^{1}$, Martin Halaj ${ }^{2}$, Andrej Vel'as ${ }^{3}$
}

\begin{abstract}
Security has been and will probably be one of the basic human needs that we work on every day. Some of the popular options nowadays is the use of modern technologies in security, which is increasingly popular with alarm systems. Mostly alarm systems are electrical security systems, which in many cases can be supplemented by various additional functions according to the owner's requirements. More often, they are also able to connect a secured object to a centralized protection center so that the owner has the possibility of verifying a declared alarm signal through the intervention of the alarm system company operator.

This article is aimed at transmitting the indicated alarm signal over a radio network to the centralized protection desk located in the monitoring and alarm receiving center with identification of the most appropriate option.
\end{abstract}

UDC Classification: 0; DOI: http://dx.doi.org/10.12955/cbup.v6.1287

Keywords: alarm transmission system, monitoring and alarm reception center, alarm management, radio network.

\section{Introduction}

Alarm systems can be understood from several points of view, since even several Slovak technical standards and regulations, as well as professional literature, do not uniformly define alarm systems. However, the individual definitions, with a slight variation, tend to agree that alarm systems are electrical installations responding to manual or automatic hazard detection. We could therefore say that an alarm system is any system whose primary purpose is to generate an alarm if the security of a protected object in which the alarm system is installed, is breached. The alarm is defined in STN EN 50131-1: 2007 as a warning in the presence of danger to life, property or the environment.

\section{Alarm transmission system}

The alarm transmission system is defined as STN EN 50136-1: 2012 as an alarm transmission device and a network used to transmit information related to the state of one or more alarm systems to one or more reporting devices of one or more alarm receiving centers. (Hofreiter and Zvaková, 2016)

The definition states that the alarm transmission system consists of three basic components, which can be expressed in a block. These are the following block components of the alarm transmission system:

- an alarm transmission device located in the protected object,

- alarm transmission path,

- an alarm transmission device located in the monitoring and alarm receiving center.

The alarm transmission system should be protected against attacks aimed at stopping a signal coming from the transmission network. No input data can prevent the alarm transmission path from performing the required function. However, if the functionality of an alarm transmission system is affected by an attack, a fault signal must be generated in accordance with the conditions for monitoring and reporting the fault of the relevant category.

To transfer the information transmitted via the alarm transmission path, it needs to be encoded. An example of an alarm transmission encoding is shown in Figure 1. (Vel'as et al., 2017)

For the transmission of information, four basic options are used in alarm transmission systems, depending on the use of the transformation / coding member. These options are:

- radio transmitter / receiver for radio signal transmission,

- a telephone communicator, in the case of the transmission of telephone signals,

- GSM module, when using mobile radio networks,

- IP communicator / LAN communicator / WIFI module for communication via Internet,

- Communicator via optical transmission paths.

\footnotetext{
${ }^{1}$ University of Zilina, Faculty of security engineering, Department of Security management, Slovakia, martin.boros@ fbi.uniza.sk

${ }^{2}$ University of Zilina, Faculty of security engineering, Department of Security management, Slovakia, martin.halaj@fbi.uniza.sk

${ }^{3}$ University of Zilina, Faculty of security engineering, Department of Security management, Slovakia, andrej.velas@fbi.uniza.sk
} 


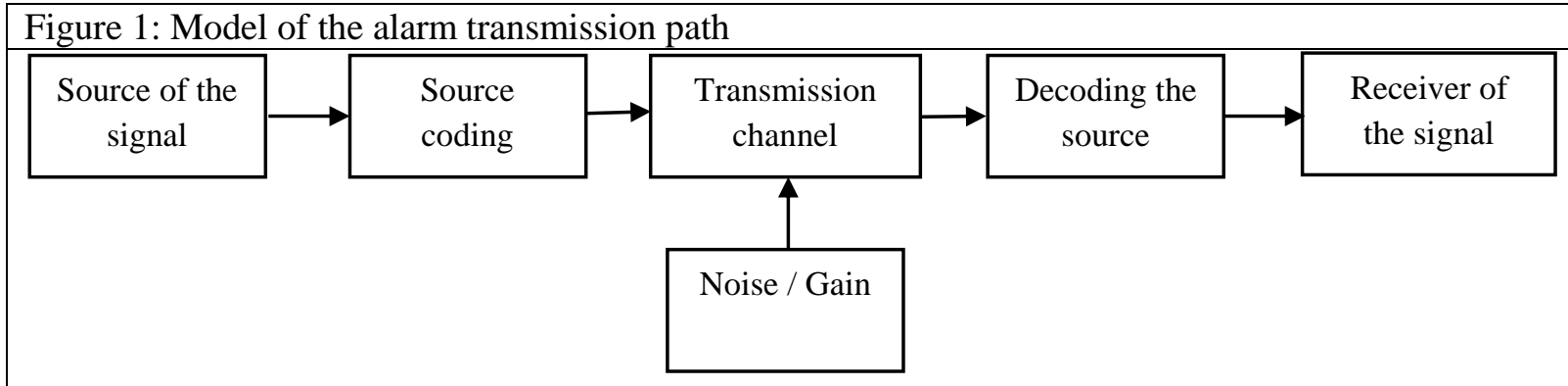

Source: Authors

The types of transmitted signals in alarm transmission systems are divided into two groups:

- Analog signal - the size of the given signal fluctuates continuously over time and its flow is smooth, without breaks and discontinuous sections. This is also called harmonic.

- Digital signal - is a signal that is discontinuous both in value and time, its intensity is maintained at a constant level over a certain time interval. These are so-called step changes of state when in a relatively brief time the signal gets one of the finite states, namely logic 1 and 0 . (Šoltés et al., 2016)

\section{Radio transmission paths}

Radio waves are electromagnetic waves with frequencies ranging from $9 \mathrm{kHz}$ to $3000 \mathrm{GHz}$ that propagate in space. A radio channel is a notification channel created using radio means (radio stations).

Due to the need for alarm transmission systems, we will only deal with the propagation of electromagnetic waves (radio waves) in the bands of very short waves - VHF (30 MHz to $300 \mathrm{MHz}$ ) and ultra-short waves - UKV (300 MHz to $3 \mathrm{GHz}$ ).

The principle of the propagation of radio waves consists in transmitting electromagnetic waves to the surrounding space. Between two places (the transmitter and receiver) is a real environment that spreads electromagnetic waves. This environment is inhomogeneous and causes the attenuation, bending or reflection of the spread of electromagnetic waves.

The device in which a signal suitable for propagation is produced is a transmitter.

A transmitter is a device in which an analog signal or a digital signal is exchanged for the frequency modulated signal input to the antenna.

The antenna is a means of transmitting (receiving) radio waves. Most antennas are the core of a wire, a dielectric rod, or a conductive surface. An antenna is a radio waveform emitted into space. (Svetlík \& Vel'as, 2016)

In radio transmission paths, the following are used:

Aerial antennas $(\lambda / 4)$ are omni-directional and are used to connect objects that are near the receiving party. It is the most commonly used antenna type because of its price and ease of installation. The disadvantage of this antenna is that the antenna is directly attached to the transmitter and its best position is with the transmitter.

A tube antenna is a thin-walled tube $(\lambda / 2)$. It is designed for direct attachment to the transmitter or for pulling off the transmitter on the console. Due to its multidirectional radiation characteristic in the horizontal plane, this antenna has better features than the more commonly used wire antenna.

The dipole antenna is an antenna $(\lambda / 2)$ designed to connect objects from $5 \mathrm{~km}$ to $15 \mathrm{~km}$ away from each other, depending on the terrain and the area. This directional antenna with near-circular (toroidal) characteristic has better parameters than the wire antenna.

Yagi's antenna is a directional multi-element antenna (dipole, reflector, directors) designed to connect larger distances (up to about $30 \mathrm{~km}$ ) where a dipole antenna is suitable. The Yagi antenna differs from the dipole by higher gain and high direction.

The Helical Antenna is designed for mounting directly on the device connector. Due to its small length, the antenna is suitable for small-area installations. It has a multi-directional radiating characteristic in the horizontal plane when mounted vertically. (Pospíšilík et al., 2017) 


\section{Monitoring and alarm reception center}

The Monitoring and Alarm Receiving Centre is a broad term designating part of a building/object designed to receive and process signals. Conversely, the centralized protection desk is part of the monitoring and alarm receiving center and represents a set of devices designed to manage and record signals.

The Monitoring and Alarm Receiving Centre is defined as a permanent service center in which information about one or more alarm systems is transmitted. In practice, instead of an alarm reception center, the concept of a centralized protection counter replaces the older concept of the alarm registration center. (Šiser and Byrtusová, 2016)

From the structural point of view of the centralized protection counter, the perimeter shell is made up of external walls, floors, ceilings, entrance / exit doors, ventilation ducts, cabling / pipe inlets, glazed areas and handling windows. An example of a typical layout of the interior of the centralized protection counter is shown in Figure 2.

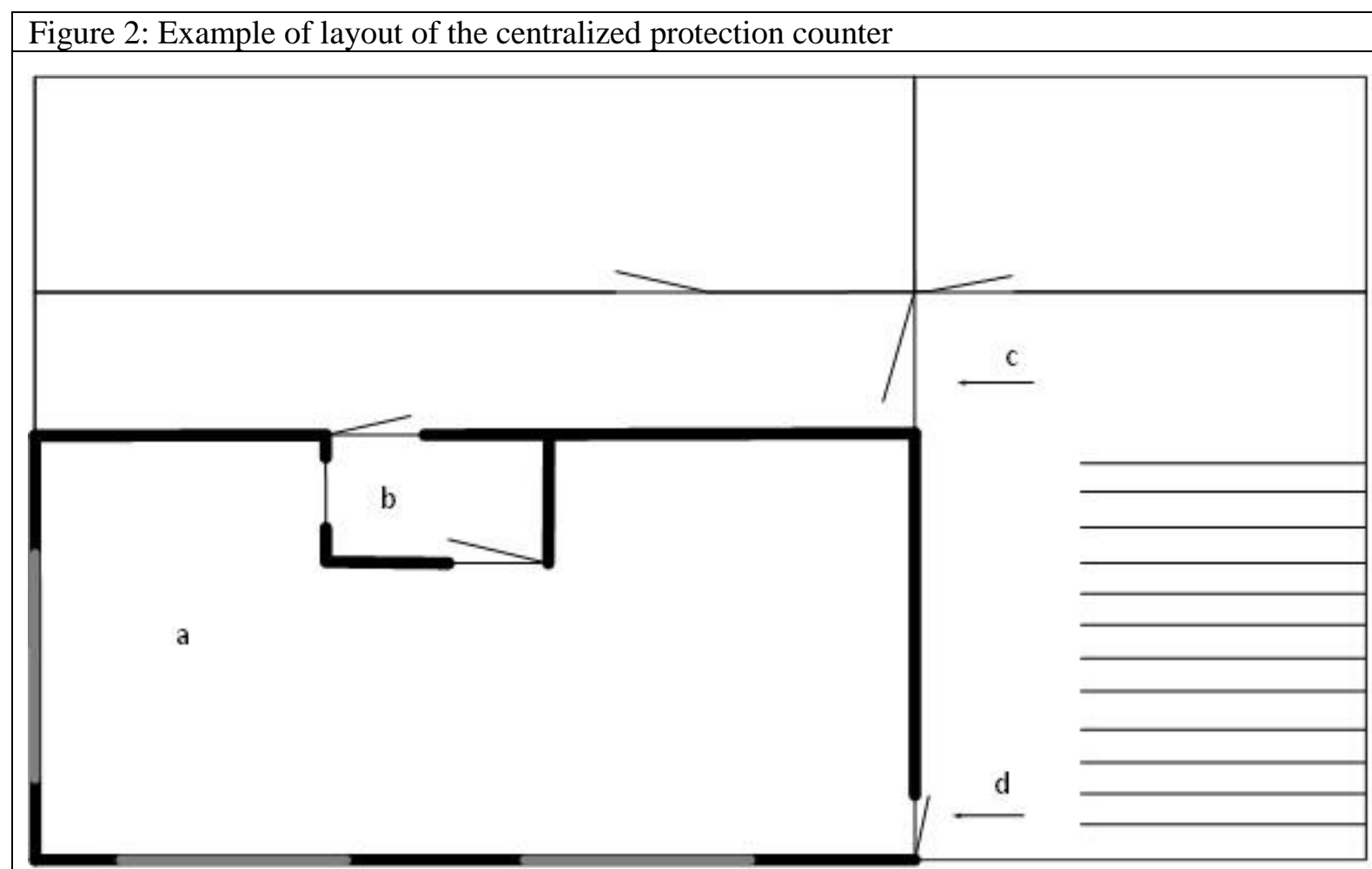

\section{The legend}

a alarm reception center

b entrance hall

c entrance part of the building

d emergency exit

glazed area

the cloak of the alarm reception center

\section{Source: Authors}

The construction elements listed in Table 2 represent the minimum requirements against physical attack. If other building materials are used, a minimum similar durability must be guaranteed.

\section{Conclusion}

The aim of this paper was to point out the possibility of using radio networks to transmit alarm messages to the monitoring and alarm receiving center. An alert message is an important piece of information that needs to be considered in terms of both content and the quality and speed of its transmission. 


\begin{tabular}{|l|l|l|}
\hline \multicolumn{2}{|l|}{ Table 1 - Minimum structural strength } \\
\hline \multirow{4}{*}{$\begin{array}{l}\text { External walls including walls } \\
\text { between dispatcher and entry } \\
\text { hall }\end{array}$} & Materials & Thickness \\
\cline { 2 - 3 } & Full walls & $\geq 200 \mathrm{~mm}$ \\
\cline { 2 - 3 } & Cast iron concrete & $\geq 150 \mathrm{~mm}$ \\
\cline { 2 - 3 } & Reinforced concrete & $\geq 100 \mathrm{~mm}$ \\
\cline { 2 - 3 } & Full steel & $\geq 8 \mathrm{~mm}$ \\
\hline Internal walls & No requirements & No requirements \\
\hline \multirow{2}{*}{ Floors and ceilings } & Cast iron concrete & $\geq 150 \mathrm{~mm}$ \\
\cline { 2 - 3 } & Reinforced concrete & $\geq 100 \mathrm{~mm}$ \\
\hline Source: Authors & & \\
\hline
\end{tabular}

Among other things, the aim was to point to the construction and interior layout of the centralized protection counter. Efforts to ensure fast and quality transmission of alarm management on a centralized protection desk are of interest to each operator. Only the high-quality and functionally configured alarm system can effectively operate the security system and to check the alarm management.

\section{Acknowledgment}

This article was published with the support of the institutional grant project IGP 201701 Experimental examination of cylindrical inserts and safety grids of various security classes.

\section{References}

Hofreiter, L., Zvaková, Z. Theoretical aspects of critical infrastructure protection, In: Durability of critical infrastructure, monitoring and testing: proceedings of the ICDCF 2016. - Singapore: Springer Nature, 2017. - ISBN 978-981-10-3246-2. - S. 139-147. - (Lecture notes in mechanical engineering. - ISSN 2195-4356).

Vel'as, A., Kutaj, M., Durovec, M. Influence of changing the parameters of the camera system on video-based motion detection, In: ICCST 2017: 51st international carnahan conference on security technology: October 23-26, 2017 Madrid, Spain. - New York: IEEE, 2017. - ISBN 978-1-5386-1585-0. - [5] s.

Šoltés, V., Štofková, K., Kutaj, M. Education as a regional development aspect, In: EDULEARN16 [elektronický zdroj]: 8th international conference on Education and new learning technologies: Barcelona (Spain), 4th-6th of July, 2016: conference proceedings. - [S.1.]: IATED Academy, 2016. - ISBN 978-84-608-8860-4. - CD-ROM, s. 3643-3647.

Svetlík, J., Vel'as, A. The safety training in the municipality, In: EDULEARN16: 8th international conference on Education and new learning technologies: Barcelona (Spain), 4th-6th of July 2016: conference proceedings. - [S.1.]: IATED Academy, 2016. - ISBN 978-84-608-8860-4. - CD-ROM, s. 1350-1355.

Pospíšilík, M., Vnenčáková, E., Kutaj, M. Intensity of EMF generated by electronic safety system devices, In: MATEC web of conferences: 21st International conference on Circuits, Systems, Communications and Computers (CSCC 2017). - ISSN 2261-236X. - Vol. 125, art. no. 02059 (2017), online, [4] s.

Šiser, A., Byrtusová, A. Multiple-criteria decision analysis applied in the process of security systems design, In: Transport means 2016: proceedings of the 20th international scientific conference: October 5-7, 2016 Juodkrante, Lithuania. - ISSN 1822-296X. - Kaunas: Kaunas University of Technology, 2016. - S. 1093-1099. 